\title{
AS NOVAS MODALIDADES DE CRIMES CIBERNÉTICOS: O CYBERBULLYING, VINGANÇA PORNOGRÁFICA E A INTERNET PROFUNDA (DEEP WEB)
}

\author{
Hugo Stéphano Rufino Belezzi \\ Universidade do Oeste Paulista - UNOESTE, Curso de Direito, Presidente Prudente, SP.
}

\begin{abstract}
RESUMO
O presente artigo abordará as novas modalidades de crimes cibernéticos como o cyberbullying, a vingança pornográfica e a internet profunda conhecida como deep web trazendo seus conceitos e definições em face ao ordenamento jurídico na atualidade, a legislação infraconstitucional que trata dos crimes cibernéticos em conjunto com esses novos tipos, trazendo inserções e alterações na legislação em vigência, os tipos de crimes mais comuns na atualidade cometidos pela internet em referência a um crescimento considerável dos casos do tipo, onde se levará em conta a necessidade de estabelecer uma adequação na legislação de forma mais específica e aplicada para coibir os criminosos que utilizam deste meio, com o intuito de trazer uma maior segurança jurídica para quem utiliza da rede mundial de computadores.
\end{abstract}

Palavras-chave: Cyberbullying, Vingança Pornográfica, Internet Profunda.

THE NEW MODALITIES IN CYBERCRIMES: CYBERBULLYING, REVENGE PORN AND DEEP WEB

\begin{abstract}
This article will address the new modalities of cyberbullying such as cyberbullying, pornographic revenge and the deep internet known as the deep web, bringing its concepts and definitions to the present legal order, infraconstitutional legislation that deals with cyber crimes together with these new types, bringing insertions and changes in the legislation in force, the most common types of crimes currently committed by the Internet in reference to a considerable growth of cases of this type, where the need to establish a more adequate legislation will be taken into account. specific and applied to curb the criminals who use this means, in order to bring greater legal certainty to those who use the global computer network.
\end{abstract}

Keywords: Cyberbullying, Revenge Porn, Deep web. 


\section{INTRODUÇÃO}

Diante dos avanços tecnológicos que a cada dia proporcionam diversas facilidades a todos os indivíduos que utilizam da rede mundial de computadores, a internet, como meio de informação, de lazer, de estudos, de compra e venda dentre outras finalidades, onde atualmente podemos obter acesso a ela por diversos dispositivos como computadores, notebooks, ultrabooks, tablets, smartphones, entre outros instrumentos utilizados pelas pessoas de forma rotineira.

Apesar das vantagens oferecidas pela rede mundial de computadores, cenário este favorável para o cometimento de crimes, em que cada vez mais as pessoas usam desse meio para a realização de diversos tipos de delitos, pois com o surgimento da internet, esses já tipificados pelo Código Penal passaram a ser praticados também pela internet, assim como surgiram novas modalidades que passaram a ser exercidas através da utilização deste meio, dando ênfase as modalidades do Cyberbullying e a vingança pornográfica e a internet profunda, conhecida como deep web.

Os crimes cibernéticos, que apesar de estarem cada vez mais presentes na realidade brasileira, carecem de legislação específica, onde houve uma considerável adequação aos dispositivos já existentes na legislação e a criação de alguns acerca de algumas infrações em face dos novos tipos de delitos cometidos pela internet.

Na elaboração deste artigo, foi utilizado o método lógico-dedutivo através da realização de pesquisas bibliográfica com/sem livros doutrinários, revistas jurídicas, artigos científicos e a análise da legislação específica e sua interferência dentro do Código Penal em face desse novo meio para o cometimento de delitos, tendo como justificativa para a elaboração desta pesquisa baseia-se na evolução dos meios de comunicação e a utilização cada vez mais intensa da rede mundial de computadores (INTERNET) e a utilização por parte de criminosos que utilizam desta ferramenta para o cometimento de diversos delitos e dos novos que vão surgindo como a vingança pornográfica e o cyberbullying e internet profunda conhecida como deep web.

\section{CYBERBULLYING}

No tocante sobre o tema, de início traremos um breve conceito sobre o termo bullying, onde segundo Barbosa (2015) palavra esta de origem inglesa e sem tradução exata para o português, tem com a característica comportamentos violentos, principalmente no ambiente escolar, contudo, esses podem se fazer presentes nos mais diversos meios, seja no âmbito familiar, como também no território profissional, mais conhecido com mobbing, apresentando-se como um sinônimo para o assédio moral.

Acerca da conceituação do tema Galia (2015) diz que:

[...]tal termo remete a condutas agressivas de forma intencional e repetitiva, sem que, no entanto, esse comportamento transgressivo apresente qualquer motivação específica e justificável, muito ao revés, apenas se baseia no fato de se maltratar, intimidar, humilhar ou mesmo amedrontar vítimas, como puro e único "objeto de diversão".

Com o crescimento de forma desenfreada dessa prática, os reflexos jurídicos vão se desencadeando de forma gradativa e continuada, onde a legislação teve que se adaptar e inovou com a criação da Lei no 13.185 de 06 de novembro de 2015 que instituiu o Programa de Combate à Intimidação Sistemática (Bullying), na qual seu artigo primeiro ${ }^{1}$ institui o combate a tal prática em todo território nacional.

Assim, para uma melhor utilização do dispositivo, a lei supracitada traz uma definição própria para esse tipo de agressão, tipificando bullying, em seu art. 1으 $\S 1$ 으, trazendo

\footnotetext{
${ }^{1}$ Art. 10 Fica instituído o Programa de Combate à Intimidação Sistemática (Bullying) em todo o território nacional.

$\S 1$ 1 No contexto e para os fins desta Lei, considera-se intimidação sistemática (bullying) todo ato de violência física ou psicológica, intencional e repetitivo que ocorre sem motivação evidente, praticado por indivíduo ou grupo, contra uma ou mais pessoas, com o objetivo de intimidá-la ou agredi-la, causando dor e angústia à vítima, em uma relação de desequilíbrio de poder entre as partes envolvidas.
} 
características que exemplificam exemplos de condutas que configuram violência, sendo estas definidas pelo seu art. 20 como as práticas através ataques físicos, insultos pessoais, comentários sistemáticos e apelidos pejorativos, ameaças por quaisquer meios, grafites depreciativos, expressões preconceituosas, isolamento social consciente e premeditado e pilhérias.

O parágrafo único do artigo 2o define a intimidação sistemática via rede mundial de computadores o cyberbullying com o intuito depreciar, incitar a violência, adulterar fotos e dados pessoais com o intuito de criar meios de constrangimento psicossocial, sendo sua classificação elencada pelo inciso VII do art. $3^{0^{2}}$ que traz o cyberbullying onde o meio virtual é utilizado para o cometimento do delito.

Freitas (2016) destaca como objetivos do referido Programa à prevenção e o combate ao bullying em todos os espaços reais e virtuais, a capacitação de equipes pedagógicas e docentes para o reconhecimento e enfrentamento do problema e a assistência psicológica, social e jurídica às vítimas e aos agressores, com intuito de tentar sua inserção no meio social. prevê, ainda, a responsabilização de escolas, clubes e agremiações recreativas caso não seja feita conscientização, prevenção, diagnose e combate à intimidação sistemática

O cyberbullying como conceito consiste na violência contra uma pessoa praticada através da internet ou de outras tecnologias relacionadas (meios virtuais). Gália (2015) assevera que a prática do cyberbullying tem como a utilização do espaço virtual para usar como intimidação e hostilizar uma pessoa, sendo de forma mais vista no ambiente escolar com colegas de sala de aula, professores, no ambiente de trabalho como chefes, subordinados, colegas de mesma hierarquia ou mesmo pessoas desconhecidas, utilizando de formas difamatórias, com insultos ou atacando de forma covardemente.

O autor supracitado ainda destaca que tal prática nada mais é do que bullying praticado por meio de novas tecnologias com a utilização da rede mundial de computadores (INTERNET).

A análise de forma profunda acerca do tema evidencia esta prática podendo configurar como uma forma mais grave, perpetuando a situação de vitimização em virtude das configurações da internet, que permite o livre e simultâneo fluxo das informações, fazendo com que as informações se propaguem de forma quase que instantaneamente, alcançando um número indefinido de internautas. Aliado a tudo isso, o que se publica na web como imagens, vídeos, fotos, palavras e recados postados em redes sociais - como Facebook, whatsapp, Instargam, Snapchat, Twitter, dentre outros, podendo ser facilmente capturado pelos demais internautas, que podem armazenar esse conteúdo, como disseminá-lo entre outras pessoas. Isto é, de outro modo, que devido ao fluxo de informações, este pode perder o controle sobre as informações postadas, podendo qualquer um armazenar esse conteúdo, como disseminá-lo entre outras pessoas.

No campo penal, dependendo por óbvio da intenção do agressor, sua prática poderá ser tipificada como hipótese de crime de ameaça, racismo, injúria, calúnia, difamação ou até lesão corporal. Em sede de aplicação Estatuto da Criança e do Adolescente, caberá a aplicação dos crimes descritos nos artigos 240 e 241-A da Lei no 8.069/90 - donde verificamos a busca pela proteção maior, tendo como bem jurídico tutelado, da liberdade e dignidade da criança ou do adolescente. (VANCIM, GONÇALVES, 2011).

$\mathrm{O}$ assédio moral virtual, muito comum nas relações de trabalho, em que algum colega quer se vingar de alguém que se destaca no serviço, na empresa. Nesse sentido, o assédio moral virtual mais comum é o do tipo horizontal, entre colegas de mesma hierarquia dentro da organização do trabalho. A prática do assédio moral por meio virtual provoca efeitos reais muitas vezes mais danosos do que ocorreria em situações análogas no assédio moral presencial. Neste sentido,

\footnotetext{
${ }^{2}$ Art. 3ํ A intimidação sistemática (bullying) pode ser classificada, conforme as ações praticadas, como:

VIII - virtual: depreciar, enviar mensagens intrusivas da intimidade, enviar ou adulterar fotos e dados pessoais que resultem em sofrimento ou com o intuito de criar meios de constrangimento psicológico e social.
} 
o cyberbullying abrange um maior número de pessoas (internet) em um menor espaço de tempo do que ocorre no assédio moral presencial.

O anonimato favorece a prática do cyberbullying, pois é possível difamar, caluniar ou injuriar alguém, agressão podendo ser direcionada a uma pessoa física ou pessoa jurídica, provocando um dano de grande extensão em um curto espaço de tempo, onde há meios do assediado virtualmente se defender ou denunciar a prática lesiva.

\section{VINGANÇA PORNOGRÁFICA}

Tecemos de início sua conceituação na qual a nomenclatura a ser utilizada vingança pornográfica ou pornografia de vingança possui raízes na expressão revenge porn (em inglês), conhecida assim nos Estados Unidos, conduta esta possui legislação especifica. Tem como referência ao ato de divulgar, através da internet, fotos ou vídeos contendo cenas de nudez ou sexo, sem autorização da pessoa que está sendo exibida, com o propósito de causar dano à vítima.

Para Fredi, Marinho e Nedez (2016, p.53) diz que:

[...]a definição da pornografia da revanche deve ser analisada tomando em separado o significado de cada termo, do qual se compreende ser a "revanche" a vingança praticada pelo (a) companheiro(a), ou, ex-companheiro (a) da vítima e, a pornografia, como a divulgação de material de cunho erótico sem autorização.

Segundo de Louzada e Rocha (2016, p. 105) tal conduta vem da prática de expor intimidade, principalmente, de jovens mulheres por seus parceiros ou ex-parceiros, como forma de ridicularizá-las, ou vingar-se por algo cometido por elas, principalmente pelo término de um relacionamento amoroso.

Observamos de início que há possibilidade de concluirmos a priori que a terminologia traz de forma enumerada os casos nos quais houve divulgação de conteúdo íntimo e ofensivo a personalidade dos sujeitos em razão de uma vingança, praticada por indivíduos que tenham ou tiveram uma relação afetiva com a vítima, e da qual os envios realizados anteriormente, mesmo que tenham sido consensuais, a exemplo, os famosos envios de "nudes" e vídeos contendo relações sexuais.

Contudo, devemos salientar que a obtenção destes materiais não chegará de forma espontânea nas mãos dos sujeitos ativos, uma vez que o dispositivo que contenham os arquivos poderão ser objeto de furto e posteriormente esses arquivos serem disseminados na rede mundial de computadores (INTERNET).

Atentamos que para além da "revanche" praticada pelo sujeito em face de outro, sobretudo, da mulher, o conceito guarda um importante aspecto envolto ao comportamento da vítima, que teria cedido o material anteriormente, tal como se o exercício de sua liberdade sexual fosse à causa primária da pornografia intentada.

Assim, o conceito e definição de vingança pornográfica, termo no qual utilizaremos neste artigo consiste na divulgação de material erótico sem autorização da parte, mediante a realização de uma vingança pessoal e sagaz, embora em muitos casos tenha sido esse material cedido de livre vontade pela vítima anteriormente na relação amorosa que mantinham.

Essa prática tem como objetivo do agressor punir a vítima, constrangendo-a mediante a exposição de fotos, vídeos ou áudios íntimos dela, isso na maioria das vezes tendo como motivação a não aceitação do término da relação amorosa ou por qualquer outro motivo que achar conveniente. Na maioria dos casos as mulheres são as principais vítimas desse delito, porém também estão sujeitos a sofrer o constrangimento os homens, os transexuais e os travestis.

As vítimas após a divulgação e disseminação do conteúdo nas redes sociais ficam marcadas e acabam pagando um preço alto. Como as consequências enfrentadas são imensas e se estendem ao ponto da exposição de toda sua vida. Com a divulgação do conteúdo no mundo cibernético, as consequências são quase irreversíveis devido a velocidade com que as informações surgem é 
tamanha, bem como a rede de pessoas recebendo, além de não se poder ter noção de quantas pessoas estão armazenando. A sociedade tende ainda a culpabilizar a vítima de forma a facilitar o compartilhamento do conteúdo e criar estereótipos e pré-conceitos. Cabe afirmar então, que são diversas as sequelas causadas pela conduta; psicológicas e econômicas, bem como o fácil alcance do objetivo do ofensor, quase impossível de remediar.

$\mathrm{Na}$ esfera penal, os operadores do direito estão utilizando de outros dispositivos contidos na legislação que procuram punir os autores da divulgação do conteúdo. A vingança pornográfica é ajustada aos crimes contra a honra, previstos no Código Penal, os quais punem quem atribuir a outrem fato ofensivo, chegando a três anos de detenção, sabendo-se que essa pena poderá, eventualmente, ser substituída por restritiva de direitos.

Dentro do nosso ordenamento jurídico pátrio, a prática do da vingança pornográfica recai como conduta tipificada pelos crimes de difamação e/ou injúria, estes previstos nos artigos $139^{3} \mathrm{e}$ $140^{4}$ do Código Penal. Ambos estão classificados como crimes contra a honra, sendo que a difamação abrange a honra objetiva da pessoa, e a injúria à honra subjetiva.

Se a vítima da vingança pornográfica for mulher e existir o vínculo afetivo entre agressor e vítima, doutrina e jurisprudência reconhecem a pornografia não consensual como forma de violência doméstica e familiar contra a mulher, de modo que será aplicada a Lei no 11.340/2006 Lei Maria da Penha, conforme previsão do seu art. 50, III. A conduta será considerada violência psicológica ou moral contra a mulher, conforme leitura do art. 70, II e $\mathrm{V}$ do referido dispositivo legal (SERENO, 2017, p. 1).

Quando a vítima da vingança pornográfica em questão for criança ou adolescente na época em que as fotos ou vídeos foram feitos, estão aplicando o art. 241 da Lei no 8.069/90 - Estatuto da Criança e do Adolescente - ECA, sendo a punição de 4 a 8 anos de reclusão e multa. As condutas envolvendo crianças e adolescentes, tipificadas nesse artigo, são oferecer, trocar, disponibilizar, transmitir, distribuir, publicar ou divulgar por qualquer meio ou adquirir, possuir ou armazenar, por quaisquer meio imagens ou vídeos de sexo explícito envolvendo menor de idade.

O projeto de lei que aborda o assunto, este já para sanção presidencial aborda a tipificação da vingança pornográfica trará três pontos que serão modificados na legislação brasileira que incluirá a expressão "comunicação" no rol dos direitos previstos no artigo 3ㅇ da Lei Maria da Penha; o reconhecimento de que a violação da sua intimidade consiste em uma das formas de violência doméstica e familiar, acrescentando o inciso VI ao art. 70 da Lei Maria da Penha e a tipificação da exposição pública da intimidade sexual, alterando o Código Penal para inserir um "novo" tipo (artigo 140-A), mais um dentre os crimes cuja persecução penal se dá através da ação privada (CASTRO, 2018).

\section{A INTERNET PROFUNDA (DEEP WEB)}

Sobre a temática em questão, de início a expressão deep web (ou internet profunda) é um universo digital fora da órbita comum dos usuários de navegação em rede. Por razões muitas das vezes desconhecida, a deep web se enquadra em um estado virtual ora considerado mito, ora considerado realidade alcançável. Na internet profunda se encontram tráficos de órgão humanos,

\footnotetext{
${ }^{3}$ Art. 139 - Difamar alguém, imputando-lhe fato ofensivo à sua reputação:

Pena - detenção, de três meses a um ano, e multa.

Parágrafo único - A exceção da verdade somente se admite se o ofendido é funcionário público e a ofensa é relativa ao exercício de suas funções.

${ }^{4}$ Art. 140 - Injuriar alguém, ofendendo-lhe a dignidade ou o decoro:

Pena - detenção, de um a seis meses, ou multa.

$\S 1$ - - O juiz pode deixar de aplicar a pena:

I - quando o ofendido, de forma reprovável, provocou diretamente a injúria;

II - no caso de retorsão imediata, que consista em outra injúria.

$\S 2$ - Se a injúria consiste em violência ou vias de fato, que, por sua natureza ou pelo meio empregado, se considerem aviltantes:

Pena - detenção, de três meses a um ano, e multa, além da pena correspondente à violência.

$\S 30$ Se a injúria consiste na utilização de elementos referentes a raça, cor, etnia, religião, origem ou a condição de pessoa idosa ou portadora de

deficiência: (Redação dada pela Lei no 10.741, de 2003)

Pena - reclusão de um a três anos e multa. (Incluído pela Lei no 9.459, de 1997)
} 
pedofilia, tráficos de drogas, canibalismo, comunidades de harckes e crackers, bibliotecas de grandes universidades, teorias acadêmicas de acesso mútuo e etc. (CORDEIRO, 2016, s.p.)

$O$ acesso em si não é ilegal, mas o anonimato torna crescente o conteúdo macabro nesse verdadeiro submundo do cybercrime que compreende desde fraudes em cartões de crédito e roubo de identidades, até bonecas sexuais humanas (crianças compradas de famílias miseráveis pelos Doll Makers e levadas a centros cirúrgicos clandestinos para que sejam transformadas em bonecas vivas que não apresentem resistência às perversões sexuais dos seus donos), conteúdo pornográfico infantil (pedofilia), anúncios de assassinos de aluguel, comércio de drogas (como o caso Silk Road, descoberto pelo FBI em 2013), vídeos com experimentos científicos realizados em humanos, fóruns sobre canibalismo, tutoriais para hacking e criação/disseminação de vírus, vídeos com mortes reais (snuff Videos), venda de armas, lavagem de dinheiro, violação de direitos autorais, etc. (PEREIRA, 2018, s.p.)

O autor supracitado traz ainda as dificuldades para a tipificação do cibercrime, onde se verifica que a deep Web amplia ainda mais essas dificuldades para o âmbito da autoria. Ou seja, se há dificuldades de ordem técnica para determinação de autoria dos cibercrimes praticados no ciberespaço, na deep Web essa determinação é impossível. (2018, s.p.)

\section{CONCLUSÃO}

No cenário atual, com a expansão acelerada das comunicações através da rede mundial de computadores (INTERNET), ficando cada vez mais explicita na sociedade o cometimento de crimes ocorridos por meios de dispositivos eletrônicos, decorrente do fácil acesso a informações diversas dos usuários que fazem uso da rede mundial de computadores para as mais variadas finalidades, desde o uso de informações de registros financeiros, em se tratando dos trâmites comerciais via rede, até dados pessoais e conteúdo íntimo como a vingança pornográfica sendo esta uma forma de violência moral, em se tratando de informações vinculadas a administração pública e ao particular como o cyberbullying sendo este como forma de assédio moral e a deep web, esta ainda com certa dificuldade em descobrir os autores que cometem crimes utilizando desta ferramenta.

Portanto, ao analisarmos as dificuldades em inserir esses delitos no nosso ordenamento jurídico, podemos dizer que já existem leis esparsas que adentraram dispositivos no âmbito penal, mas estamos iniciando, em "passos curtos", uma nova realidade social inserida na Legislação Brasileira.

\section{REFERÊNCIAS}

BARBOSA, Maria Ester. A responsabilidade civil e o bullying. Disponível em: < https://mariaester.jusbrasil.com.br/artigos/220409704/a-responsabilidade-civil-e-o-bullying>. Acesso em: 03 jun. 2018.

BRASIL. Constituição da República Federativa do Brasil de 1988. Disponível em: <http://www.planalto.gov.br/ccivil_03/constituicao/constituicaocompilado.htm>. Acesso em: 15 mai. 2018.

BRASIL. Código Penal. Decreto-lei no 2848, de 7 dezembro de 1940. Disponível em:<http://www.planalto.gov.br/ccivil_03/decreto-lei/Del2848compilado.htm>. Acesso em: 15 mai. 2018.

BRASIL. Lei no 8069, de 13 de julho de 1990. Dispõe sobre o Estatuto da Criança e do Adolescente e dá outras providências. Disponível em: <http://www.planalto.gov.br/Ccivil_03/leis/L8069.htm>. Acesso em: 15 mai. 2018. 
BRASIL. Lei no 11340, de 07 de agosto de 2006. Cria mecanismos para coibir a violência doméstica e familiar contra a mulher, nos termos do § 80 do art. 226 da Constituição Federal, da Convenção sobre a Eliminação de Todas as Formas de Discriminação contra as Mulheres e da Convenção Interamericana para Prevenir, Punir e Erradicar a Violência contra a Mulher; dispõe sobre a criação dos Juizados de Violência Doméstica e Familiar contra a Mulher; altera o Código de Processo Penal, o Código Penal e a Lei de Execução Penal; e dá outras providências. Disponível em: <http://www.planalto.gov.br/ccivil_03/_ato2004-2006/2006/lei/l11340.htm>. Acesso em: 15 mai. 2018.

BRASIL. Lei no 11829, de 25 de novembro de 2008. Altera a Lei no 8.069, de 13 de julho de 1990 Estatuto da Criança e do Adolescente, para aprimorar o combate à produção, venda e distribuição de pornografia infantil, bem como criminalizar a aquisição e a posse de tal material e outras condutas relacionadas à pedofilia na internet. Disponível em: <http://www.planalto.gov.br/ccivil_03/_ato2007-2010/2008/lei/l11829.htm>. Acesso em: 15 mai. 2018.

BRASIL. Lei $n$ N 12737, de 30 de novembro de 2012. Dispõe sobre a tipificação criminal de delitos informáticos; altera o Decreto-Lei no 2.848, de 7 de dezembro de 1940 - Código Penal; e dá outras providências. Disponível em: <http://www.planalto.gov.br/ccivil_03/_ato20112014/2012/lei//12737.htm>. Acesso em: 15 mai. 2018.

BRASIL. Lei no 12965, de 23 de abril de 2014. Estabelece princípios, garantias, direitos e deveres para o uso da Internet no Brasil. Disponível em: <http://www.planalto.gov.br/ccivil_03/_ato20112014/2014/lei//12965.htm>. Acesso em: 15 mai. 2018.

CASTRO, Pablo Domingues Ferreira. Lei sobre vingança pornográfica é mais um aceno para Direito Penal simbólico. Revista Online Consultor Jurídico. Disponível em: < https://www.conjur.com.br/2018-fev-22/lei-vinganca-pornografica-aceno-direito-penalsimbolico>. Acesso em: 30 mai. 2018.

CORDEIRO, Erick. O alcance jurídico da deep web. JUSBRASIL. Disponível em: < https://erickcordeiro.jusbrasil.com.br/artigos/318501353/o-alcance-juridico-na-deepweb?ref=topic_feed>. Acesso em: 05 jun. 2018.

FREDI, Alice Rossato; MARINHO, Isabella Carvalho; NEDEL, Nathalie Kuczura. Pornografia da revanche: o grande mal da sociedade informacional. In: . Direito da Informática: da Normativa e da negativa a emergência. 1ạ coletânea. Santa Maria: Fadisma, 2016. p. 52-61.

FREITAS, Filipe Augusto Cursino. Comentário sobre a lei "antibullying" lei no 13.185, de 06 de novembro de 2015 uma tentativa de solução. Revista Psychiatry on line Brasil. São Paulo, v. 21, n. 2, 2016. Disponível em: < http://www.polbr.med.br/ano16/pia0216.php>. Acesso em: 04 jun. 2018.

GALIA, Rodrigo Wasem. Cyberbullying: conceito, caracterização e consequências jurídicas. Disponível em: <http://emporiododireito.com.br/leitura/cyberbullying-conceito-caracterizacao-econsequencias-juridicas >. Acesso em: 03 jun. 2018. 
LOUZADA, Marcelle Cardoso; ROCHA, Nathalia Falco. A transição entre sexting e a pornografia da revanche na nova sociedade do espetáculo. In: . Revolução Digital: análises e perspectivas das novas tecnologias. Vol 1. 1a ed. Santa Maria: Fadisma, 2016. p.103-117.

PEREIRA, Marcelo Alves. A tutela jurisdicional da deep web. Disponível em: < https://alvespereiraadv.jusbrasil.com.br/artigos/356366589/a-tutela-jurisdicional-na-deepweb?ref=topic_feed>. Acesso em: 10 jun. 2018.

SERENO, Giordano Alan Barbosa. Pornografia não consensual: o problema da falta de tipificação penal. Disponível em: <https://jus.com.br/artigos/63138/pornografia-nao-consensual-oproblema-da-falta-de-tipificacao-penal/2>. Acesso em: 25 mai. 2018.

VANCIM, Adriano Roberto; GONÇALVES José Eduardo Junqueira. Os cybercrimes e o cyberbullyingapontamentos jurídicos ao direito da intimidade e da privacidade.Disponívelem:<http://www.google.com.br/url?sa=t\&rct=j\&q=\&esrc=s\&frm=1\&source =web\&cd=7\&ved=0CE4QFjAG\&url=http\%3A\%2F\%2Fbd.tjmg.jus.br\%2Fjspui\%2Fbitstream\%2Ftjmg \%2F395\%2F1\%2FD4v1992011.pdf\&ei=r8qbUvP9AejesATv6IBo\&usg=AFQjCNHbasQKAKXwReAMw 5IBnA-ucU4uRw>. Acesso em 02 jun. 2018. 